\title{
Procedure for Determining Integral Index of Motor Transport Enterprises Competitiveness as the Basis of Shaping Regional Programs of Transport Infrastructure Development
}

\author{
Asiiat Mottaeva ${ }^{1, *}$ \\ ${ }^{1}$ Moscow State University of Civil Engineering, Yaroslavskoe shosse, 26, Moscow, 129337, Russia
}

\begin{abstract}
Transport system of a region is a complex socio-economic and technical system closely related to all sectors of national economy. In the present paper, the current problems in all areas of motor transport enterprises performance are identified to provide the enterprises' sustainable functioning and development; an attempt is made to find solutions to the problems of ensuring motor transport enterprise competitiveness. The proprietary methodology for calculating an integral competitiveness index of an enterprise presupposes the justification of the indicators characterizing the competitiveness and weighting coefficients; justification of the choice of information sources and methods of its collection; summarizing and grouping the input data; calculation of intermediary, generalized, and resulting indicators; identification of the integral evaluation of internal and external environment influence on competitiveness; rating enterprises competitiveness. Obtaining an integral index allows comparing the competitiveness of the enterprises in regional economy, to choose an enterprise with a higher competitiveness index (compile a rating for the region's enterprises) in order to provide targeted support and to include it into the cluster policy of the region.
\end{abstract}

\section{Introduction}

Infrastructure basis of modernization relies on the improvement of regional transport infrastructure. The formation of the regional transport service market determines spatial integration of commercial activities, develops interregional, interindustrial, and international links, multifaceted rational deployment of human, nature, financial, and other resources of the region. To this end, a need to study specifics of the transport system development within particular regions emerges. To solve these tasks, Program on Regional Transport Infrastructure Development should be developed and adopted that would comprise a set of socio-economic, production, $\mathrm{R} \& \mathrm{D}$, and other programs, plans and measures linked with the assets, deadlines and contractors, and aimed at design and

* Corresponding author: asya@,front.ru 
implementation of creation and development of an effective transport service system in the region.

Recently, the car park has been redistributed among the subjects of road transport service market in favor of private owners. Continuous growth of cargo traffic flow and increasing competition determine a decrease in the number of big and middle-sized motor transport enterprises (MTE) $[3,9,10]$.

It is very important to identify the current problems in all areas of a MTE performance to ensure its sustainable functioning and development with due regard to the MTE's goals, and within the framework of designed strategies, it is crucial to find the solutions to these problems using the methods at hand and developing new solutions[8,14].

It is quite a challenging task to try to find a solution to problems of ensuring MTE competitiveness without fully comprehending its place in the overall system of business problems the MTE faces.

A permanent problem for aMTE is to increase the profit in a competitive environment. The goal of profit increase can be achieved by step-by-step problem solution.

Since aMTE competitiveness problem is, first of all, associated with the need to solve organizational problems to achieve economic parameters, further organizational and economic issues of aMTE performance are identified and discussed in details.

The problems of a MTE competitiveness are ones of the most important organizational economic problems. These problems include the lack of the recognized model for assessing MTE competitiveness; immaturity of the current models targeted at the industrial enterprises; diversity of indexes of the MTE competitiveness evaluation and their difficulty of formalizing; the suggested methods for evaluating competitiveness of enterprises do not allow accounting for the changes made by MTEsin order to improve their organizational economic performance, including the ones owing to the necessity to reduce the MTE risks, etc.

The problem of a MTE competitiveness is complex. The existing organizational economic approaches to its solution do not solve the problem of ensuring the MTE competitiveness. The results of analysis of a MTE performance in Russia illustrate the need to find the ways to solve the problem of a MTE competitiveness via reduction of MTErisks $[1,4,6]$

Selection and justification of the indicators and the evaluation criteria are the most crucial stages in developing a MTE competitiveness evaluation methodology. Its correspondence to real settings where the object works is a basic requirement for practical application of a MTE competitiveness evaluation methodology results[2,12, 17]. Insufficient correspondence of the methodology to the real production settings leads to the failure of organizational measures based on this methodology to compete with the methodologies based on experts' experience and intuition. Thus, the challenge is to select the set of indicators that would be, on the one hand, sufficiently justified and complete, but, on the other hand, not very time-consuming for its real use.

\section{Methodology}

A prerequisite for the methodology to be adequate is the usage of the indicators concerning both internal possibilities and potential of a MTE and a consumer's vision and preferences to the extent permitted by the assets of the enterprise. The evaluation of some indicators 'applicability rests on both the internal information sources and mass media data, as well as on the information about the competitors $[5,7,18]$.

In selecting a set of indicators one must not forget that a MTE integral competitiveness indicator characterizes its potential. 
For purposes of the present work, it is reasonable to specify the following principles, on the basis of which risk-based MTE competitiveness indexes should be formed $[4,13]$ :

1. Coverage principle- a MTE capability to fully comply with its obligations to its clients in the context of external and internal factors;

2. Consistency principle -evaluation indicators should analyze the influence of unfavorable events on a MTE competitiveness level;

3. Principle of balance of interests, where indicator system should take into account both a MTE's and its clients' interests:

4. Comparability principle means the need to compare the obtained calculated values for the analyzed MTE indicators with the best values of the main competitors (MTE of a strategically competitive group);

5. Principle of simplicity in collecting and calculating describes the use of mathematical tools comprehensible for a wide range of users. This principle is suggested within this research to provide a MTE a sufficient and available tool to evaluate its competitiveness in order to ensure it. This principle should not be applied for large MTEs, since the more complex a research object is, the more parameters are required to its characterization and identification among other similar objects. If this is the case, a large MTE should extend a set of indicators for competitiveness evaluation and deepen their structure, which will inevitably result in increased labor intensity of the calculations.

To choose the adequate set of indicators, for the groups of indicators their compatibility with the principles of a MTE indicators set formation was analyzed in order to meet the requirements of the present paper.

Having analyzed the competitiveness evaluation indicators proposed in the scientific literature we grouped them in Table $1[4,16]$

Having analyzed these and other indicators and compared them by their influence on a MTE integral competitiveness index, and taking into consideration the results of our survey among MTE specialists conducted for the present research, we identified a group of consolidated indicators with their further specifications.

Below a set of summarizing competitiveness factors necessary to achieve the resulting MTE competitiveness indexis discussed, the arguments to justify their choice in a MTE competitiveness evaluation methodology are given, and the calculation methods are presented.

The summarizing indicators of a MTE competitiveness are

1. factors characterizing a transport service;

2. factors determining a brand of the MTE;

3. factors characterizing the MTE market positions:

4. factors characterizing the MTE efficiency.

Table 1.Results of the analysis of indicator groups compatibility with principles of a MTE competitiveness indicator sets formation.

\begin{tabular}{|c|c|c|c|c|c|}
\hline \multirow[b]{2}{*}{$\begin{array}{l}\text { Generalized groups of } \\
\text { competitiveness indicators }\end{array}$} & \multicolumn{5}{|c|}{ Principles of MTE competitiveness indicator formation } \\
\hline & $\begin{array}{l}\text { coverage } \\
\text { principle }\end{array}$ & $\begin{array}{l}\text { consistency } \\
\text { principle }\end{array}$ & $\begin{array}{l}\text { principle } \\
\text { of balance } \\
\text { of } \\
\text { interests }\end{array}$ & $\begin{array}{l}\text { comparability } \\
\text { principle }\end{array}$ & $\begin{array}{l}\text { principle } \\
\text { of } \\
\text { collection } \\
\text { and } \\
\text { calculation } \\
\text { simplicity }\end{array}$ \\
\hline $\begin{array}{l}\text { Resource efficiency } \\
\text { (production means, } \\
\text { financial, human) }\end{array}$ & no & no & no & yes & no \\
\hline
\end{tabular}




\begin{tabular}{|l|l|l|l|l|l|}
\hline $\begin{array}{l}\text { Effectiveness of work in } \\
\text { separate performance areas } \\
\text { (purchase, production, } \\
\text { innovation, marketing, sale, } \\
\text { etc.) }\end{array}$ & no & no & no & yes & no \\
\hline Stability of an enterprise & yes & yes & no & no & no \\
\hline $\begin{array}{l}\text { Goods/service } \\
\text { competitiveness }\end{array}$ & yes & yes & yes & yes & yes \\
\hline $\begin{array}{l}\text { Occupied competitive } \\
\text { position }\end{array}$ & yes & yes & yes & yes & yes \\
\hline $\begin{array}{l}\text { Image, media image, } \\
\text { popularity, recognition }\end{array}$ & yes & yes & yes & yes & yes \\
\hline
\end{tabular}

No- indicator group does not correspond to the principle; yes - indicator group corresponds to the principle.

To calculate the resulting MTE competitiveness index following the principle of adequate MTE competitiveness evaluation methodology an additive function should be applied as the most easily available for calculation and lacking any disadvantages of multiplicative function when a zero value of one of the indicators results in zero value for the resulting competitiveness indicator.

The formula to calculate a MTE competitiveness index $[4,15]$ is as follows:

$$
C_{M T E}=C_{T S} X_{1}+I_{I} X_{2}+I_{M S} X_{3}+I_{O F} X_{4}
$$

Where $C_{M T E}$ is aMTE resulting competitiveness index, $C_{M T E} \in(0 ; 1]$;

$C_{T S}$ is market model standardized value of competitiveness index of a transport service;

$I_{I}$ is is model standardized value of the MTE image indicator;

$I_{M S}$ isis model standardized value of the MTE relative market share indicator;

$I_{O F}$ isis model standardized value of the MTE obligation fulfillment indicator;

$\mathrm{x}_{i}$ is weighting coefficient value belonging to $i$-evaluative indicator.

Depending on the MTE evaluation method it is necessary to consider the industry to which belongs this or that enterprise under discussion. For a MTE a key factor determining its competitiveness is transport service (TS). In this paper TS is defined as a result of a MTE performance aimed to satisfy the cargo owners' needs for transporting the cargo, additional associated services, as well as to provide the warranties of quality for the services and compensate for the damage in case of the unsafe shipment due to a fault of the MTE workers.

With the multifacetedness of the quality indexes, the following set of indicators is believed to be necessary and efficient to calculate TS quality indexes:

1) time keeping in shipment $\left(T K_{S}\right)$;

2) safety of the transported cargoes $\left(S_{T C}\right)$;

Here is the formula to calculate the indicators $Q_{T S}[4]$ :

$$
Q_{T S}=T K_{S} i+S_{T C} j
$$

Where $Q_{T S}$ is TS quality indicators;

$T K_{S}$ is the standardized value of shipment time keeping indicator;

$S_{T C}$ is the standardized value of transported cargo safety indicator;

$i, j$ are the weighting values of $Q_{T S}\left(\sum i, j=1\right)$;

Since the indicators have different values, one needs to standardize them to use an additive function. The analysis of the suggested indicators witnesses the sufficiency of the 
indicators proposed for the calculation. The economic indicators should be considered as TS quality indicators together with the time keeping and safety indicators.

Shipment cost efficiency indicators are one of the most important for a MTE, since they reflect the efficiency of the shipment process, although they are the least interesting for the cargo owners.

It should be noted that to calculate an integral indicator the following indicators are used here: TS purchase price, as well as the consumption expenses, which are more available for calculation and more important for the cargo owners (a MTE clients);service quality; technical level of the vehicles in accordance with their value-added use; personnel potential, that is the potential of knowledge and management skills ensuring the MTE development; range of assortment of the MTE additional associated services characterizing the MTE marketing potential; quality warranties or support service; image is important to support and maintain the positive perception of the MTE by the future clients, including with the official MTE web-site; MTE reference in mass media or public recommendations in other information sources; publicity of an open list of client-companies whose names are popular (brand, known trademark) and which use the MTE services, allowing to inform a wide audience on this fact officially; market shares one of the key indicators among an enterprise competitiveness evaluation methodologies suggested by different authors in scientific literature; MTE shipment volume; obligation fulfillmentis a completely new MTE competitiveness factor suggested by the author based on the results of the present research. Due to the specificity of its business activities, the MTE is liable to take care of the shipped cargo in terms of the price for the service and the value of the cargo, which may exceed TS value in several times.

The research of a MTE business activities at the present paper reveals that consumption expenses are the least valuable in the structure of the MTE competitiveness. At the same time one cannot but take this indicator into account.

The present paper considers small enterprises with narrow specialization due to the impossibility (expensiveness) to serve the vehicles of different purposes. These enterprises (individual entrepreneurs) rely on the market price in the segments of their business activities in choosing the price formation method. Some MTEs owing their regular customers and thus steadily developing could afford the price higher than the market one. The best value of the price corresponds to its minimum value. The generalized TS competitiveness index decreases with the exceeding price consumption indicator.

The suggested indicators are important for the cargo owners wishing to save money in choosing a small MTE. Typically, the recommendations to work with several MTEs could become crucial in searching for the information about them.

MTE TS evaluation indicators are schematically summarized in Figure 1 [4]

\section{Conclusion}

Cluster approach to the spatial distribution organization, as shown above, accumulates the forces of the MTE in particular regions limited by transport distribution centers of the region.

The obtained integral index could serve the basis for the ratings of enterprises and could be used as a criterion for targeted support or for enterprise selection in regional specialpurpose programs of transport infrastructure development support in the region [5].

The methodology of MTEs rating (Mottaeva, 2012) presupposes the following steps:

1. Selection of enterprises to rate and compare.

2. Justification of indicators and groups of rational and acquired competitiveness factors.

3. Standardization of different indicators allowing measuring the result.

4. Summarizing and grouping the input data. 
5. Identification of the weighting indicators to compare the chosen competitiveness factors.

6. Calculation of competitiveness indexes for the enterprises under discussion.

7. Evaluation of influence of external and internal environment changes on competitiveness level.

8. Formation of enterprises rating for the region with a view to increase the efficiency of transport support for the region's clusters.

Thus, the calculation of the integral index allows forming competitiveness rating of enterprises and shaping the long-term plans for infrastructure transport support for the region's industrial clusters in accordance with of these enterprises' market shares.

\section{References}

1. A.A.Bachurin,Marketing naavtomobilnom transporte(Akademiya,Moscow, 2009)

2. R.A. Fatkhutdinov, Konkurentosposobnostorganizatsii v usloviyakhkrizisa: ekonomika, marketing, menedzhment (Marketing,Moscow, 2002)

3. A.D.Khmelnitskiy, Ekonomikaiupravlenienagruzovomavtomobilnomtransporte (Akademiya, Moscow,2010)

4. A. B.Mottaeva,Metodologiyaprostranstvennogoraspredeleniyapredprinimatelskikhstru kturregionanaosnoverazvitiyatransportnoyinfrastruktury (DSc Thesis, St. Petersburg, 2012)

5. An.B. Mottaeva, As.B. Mottaeva. International Journal of Applied Engineering Research10(23), 43446(2015)

6. URL: http://niiat.ru/news/171/

7. A. E.Rubtsov, Strategiyaupravleniyatransportnympredpriyatiem (Saint Petersburg State University of Engineering and Economics Press.,St. Petersburg, 2007)

8. E.A. Safronov, Transportnyesistemygorodoviregionov (ASV, Moscow, 2005)

9. M.E. Porter, On Competition(Harvard Business School Press, Boston,1998)

10. M.E. Porter, The Economic Performance of Regions (Regional Studies, Boston, 2003)

11. Carfax Publishing37, 6/7 (2011)

12. N.G. Verstina, E.M. Akimova, T.N. Kisel, N.N. Taskaeva, Asian Social Science11, 14(2015)

13. A. Mottaeva, MATEC 73, 07020 (2016)

14. A.Mottaeva, A.Zheltenkov, I.Stukanova, S.Ryabichenko, S.Zhuk, MATEC Web of Conferences73, 07026 (2016)

15. An. B. Mottaeva,As. B. Mottaeva, International Journal of Applied Engineering Research 10(23), 43446-43449 (2015)

16. An. B. Mottaeva, As. B. Mottaeva, International Journal of Applied Engineering Research 11(9),6808-6816 (2016)

17. T. Miroshnikova, N. Taskaeva, MATEC 73, 07006 (2016)

18. A. Pimenova, S. Kuzmina, N. Morozova, A. Mottaeva, MATEC 73, 07018 (2016) 